\title{
Discussion: The adverse health and safety influence of subcontracting
}

Patrick Manu BSc(Hons)

Research Student and Visiting Lecturer, University of Wolverhampton, UK Nii Ankrah MSc, PhD, ICIOB, FHEA

Senior Lecturer, University of Wolverhampton, UK

David Proverbs PhD, PGCertEd, FCIOB, FHEA

Professor of Construction Management and Head of Construction and

Infrastructure Department, University of Wolverhampton, UK
Subashini Suresh MEng, PhD, PGCLTHE, FHEA

Senior Lecturer, University of Wolverhampton, UK

Robert Leslie Ibell BSC

ICE, London, UK

\section{Contribution by R. L. Ibell}

The premise by Manu et al. (2011a) is a wide generalisation subcontractors will have more accidents because it is they who are actually doing the work.

The suggestion that the law/codes of practice alone will solve the problem is incorrect in my opinion. The law will encourage, but also breeds a cynical compliance culture among main contractors seeking 'to cover their back'. It is interesting that this briefing article followed a paper on encouraging safety through procurement - doesn't this apply equally to main contractors?

The way to improve health and safety among subcontractors is for the main contractor to set behavioural standards, use carrots instead of sticks with the supply chain and work together to improve safety instead of beating up and loading bureaucracy onto the supply chain. They should get alongside their supply chain and treat them as partners in cost and safety.

We could work with the supply chain in a better manner if we could come up with better ways to measure safety behaviours/ culture. Seeing it in terms of paperwork and accidents only leads to cynicism and fiddling the figures. Perhaps we should look at how the subcontractor rewards good safety attitudes, positive suggestions and safe behaviours. Let them propose what is important to their health and safety and measure that.

\section{Authors' response}

Although health and safety (H\&S) legislation is not the only driver of H\&S improvement, it is a key driver. For that reason, efforts to entrench any benefits that can be derived from the regulations are reasonable. Working together with the supply chain to improve H\&S is very important and Regulation 5 of the Construction (Design and Management) Regulations 2007 (i.e. cooperation) (http://www.hse.gov.uk/ construction/cdm/legal.htm) looks at that.

The significance of other efforts to improve H\&S (such as behaviour-based safety) can, however, not be ignored as H\&S is multi-faceted. For instance, findings from ongoing research by the authors, some of which have been published (Manu et al., 2011b), indicate that, beyond the regulatory requirements, some main contractors have their own in-house practices/ measures aimed at mitigating the H\&S influence of subcontracting. This indicates the complementary role played by legislation and other measures aimed at achieving a safer construction industry. While it is therefore not the position of the authors that legislation is the sole means to achieving H\&S improvement, its importance can not be ignored and any efforts that can make it more effective should not be overlooked.

\section{REFERENCES}

Manu P, Ankrah N, Proverbs D and Suresh S (2011a) Briefing: The adverse health and safety influence of subcontracting.

Proceedings of the Institution of Civil Engineers -

Management Procurement and Law 164(4): 169-171.

Manu P, Ankrah N, Proverbs D, Suresh S and Adukpo E

(2011b) Managing the adverse health and safety impact of subcontracting: findings of a qualitative inquiry. In Proceedings of West Africa Built Environment Research (WABER) Conference, Accra, Ghana (Laryea S, Leiringer $\mathrm{R}$ and Hughes W (eds)). See http://www.waberconference. $\mathrm{com} /$ (accessed 04/10/2012). 